\title{
Dalinianas e outras metamorfoses imagéticas
}

Anna Maria Balogh

Professora livre-docente (ECA/USP) e Professora Titular da Pós-Comunicação UNIP. E-mail: baloghfenix@hotmail.com

Resumo: A partir das propostas do seminário de Pós-Graduação ministrado na Universidade Paulista (UNIP) Imagens e Travessias: suportes, experimentações, transmutações e transmediações, em 2014, a autora reflete sobre alguns processos de metamorfose imagética. Algumas obras do pintor catalão Salvador Dalí servem como inspiração para apontar desafiadores processos de transformação da imagem, num amplo leque que vai desde metamorfoses intra-textuais até passagens de suportes como foto para pintura, instalação e até mesmo a serialização em objetos de grife. Estabelecem-se também paralelos entre tais procedimentos na arte e na comunicação, sempre com base na semiótica visual, o suporte metalinguístico do artigo.

Palavras-chave: imagens; suportes; experimentações; transmutações; metamorfoses.
Abstract: A course given to doctorate students on Metamorphosis of the Images both in Arts and Communication, is the conceptual basis to this article. Inspired in some of the works of the Spanish painter, Salvador Dali, the author briefly analyzes subversive intra and intertextual transformations in images, as for instance, a photo into a picture, followed by transmutation of the picture into installation, an installation inspiring the manufacture of refined signature objects. When suitable, some artistic procedures are compared with similar procedures repeated in mass communication. Visual semiotics is the theory that supports the analysis of the art works.

Keywords: images; media; trials; transmutations; metamorphoses.

\section{INTRODUÇÃO}

O universo das imagens presente de forma avassaladora na sociedade contemporânea vem-se transformando com tal velocidade que a crítica não pode se eximir de descortinar os procedimentos mais marcantes utilizados no processo de metamorfose constante do universo visual. A crítica preserva, assim, a memória de transformações significativas no interior do mundo contemporâneo caracterizado pela velocidade, pela dromoscopia, tal como concebida por Paul Virilio a partir da etimologia grega da palavra. O objetivo do artigo, portanto, é o de refletir sobre algumas das experimentações pontuais realizadas ao longo da diacronia nas artes, em permanente diálogo com a comunicação. Dentro dessa linha de pensamento cabem as observações de Iuri Lotman, sobre a cultura considerada como uma memória coletiva, um mecanismo de conservação 
1. LOTMAN, Iuri. La Memoria a la Luz de la Culturologia. In: CriteriosRevista de la Literatura y las Artes, Estética y Culturologia. La Habana-Cuba, enero-junio 1994, n. 31, p. 225

2. LOTMAN, luri. La Memoria a la Luz de la Culturologia. In: Criterios - Revista de la Literatura y las Artes, Estética y Culturologia. La Habana-Cuba, enero-junio 1994 n. 31, p. 226.

3. ALBELTI, Leon Batista. Da pintura. In: LICHTENSTEIN, Jacqueline (org.). A Pintura. A Figura Humana. São Paulo: Editora 34, 2004, v.6, p. 30.

4. ECO, u. \& Calabrese, O. El Tiempo en la Pintura Milan: Mondadori, 1987, p. 115.

5. VERDONE, M; MIRACCO R. Giacomo Balla 1894-1946. Da io Balla a Ball'io. Mostra e Catálogo. São Paulo: Pinacoteca do Estado, 12 de maio - 30 de jun., 2000. e transmissão de textos, bem como de elaboração de outros novos. Em suma a cultura elabora seus paradigmas de conservação e esquecimento de textos ${ }^{1}$.

Uma das formas de se avaliar o peso e a influência das manifestações artísticas mais marcantes no âmbito da cultura, é a de detectar as respostas que instigam, gerando farta intertextualidade, bem como diálogos entre artes e mídias, de ver as novas formas criadas, ou ainda, a migração de imagens artísticas para universos não previstos, como o dos objetos. A maioria das novidades propostas não nasce do vazio, com frequência o inesperado conversa com a tradição, em experimentações e subversões surpreendentes: o novo na arte. Como diz Lotman, com o tempo, muda o sistema de códigos culturais, e muda o paradigma de memória-esquecimento².

Há um espaço intermediário no qual, com frequência, arte e comunicação se encontram, basta lembrar a trajetória de sucesso de Hans Donner na televisão brasileira. Formado em design na Áustria, foi um elemento fundamental na grande reformulação visual da Rede Globo incentivada por Boni e Walter Clark quando a emissora festejava sua primeira década de existência. E pensar que tudo teve origem no desenho do logo da emissora feito num guardanapo de papel da Swissair. Conforme entrevista concedida à About por Donner, o seu desenho exigiria um gênio matemático em computação para realizá-lo dez anos depois! O artista comenta também, que muito embora goste de tecnologia, faz grande parte de seu trabalho com as mãos. Os veios arte e comunicação se unem na emissora a partir de 1980 e redundam na trajetória única do artista responsável pelo perfil visual da Globo e por algumas das mais bem logradas vinhetas de abertura de sua programação.

Ao longo da diacronia das artes sempre houve artistas de vanguarda em busca dos modos de expressão originais e subvertedores. O presente com sede de futuro. Um dos movimentos mais ricos nesse sentido parece ser aquele da busca das artes estáticas pela representação do movimento antecipando um processo que conheceria seu ápice na sétima arte, o cinema. Eis um caminho que vale a pena recordar de forma bem sucinta. Como é sabido, mesmo os artistas do pretérito visavam vencer de algum modo o caráter estático próprio do pictórico por meio das representações possíveis do movimento em cada época, mesmo num pretérito longínquo Leon Batista Alberti em seu tratado de pintura se preocupava com as formas de sugerir ou acentuar os movimentos do corpo ${ }^{3}$.

Em períodos mais próximos à contemporaneidade, as Artes Plásticas buscaram o movimento em quadros futuristas como os de Giacomo Balla, visando enfrentar os desafios de captar o dinamismo incessante da vida por meio da pintura. Tentativa vencida com brilhantismo em quadros como Muchacha corriendo en el balcón, $1912^{4}$, baseando-se para tanto no preceito científico da persistência retiniana do imagético. Algo similar ocorre na fotografia ao final do século XIX nas experimentações "cronofotográficas" de Jules Marey com uma câmera que fotografava a intervalos predeterminados de tempo, como em Um golpe de martelo, $1890 \mathrm{ca}^{5}$. 
Figura I - Muchacha corriendo en el balcón de Giacomo Balla

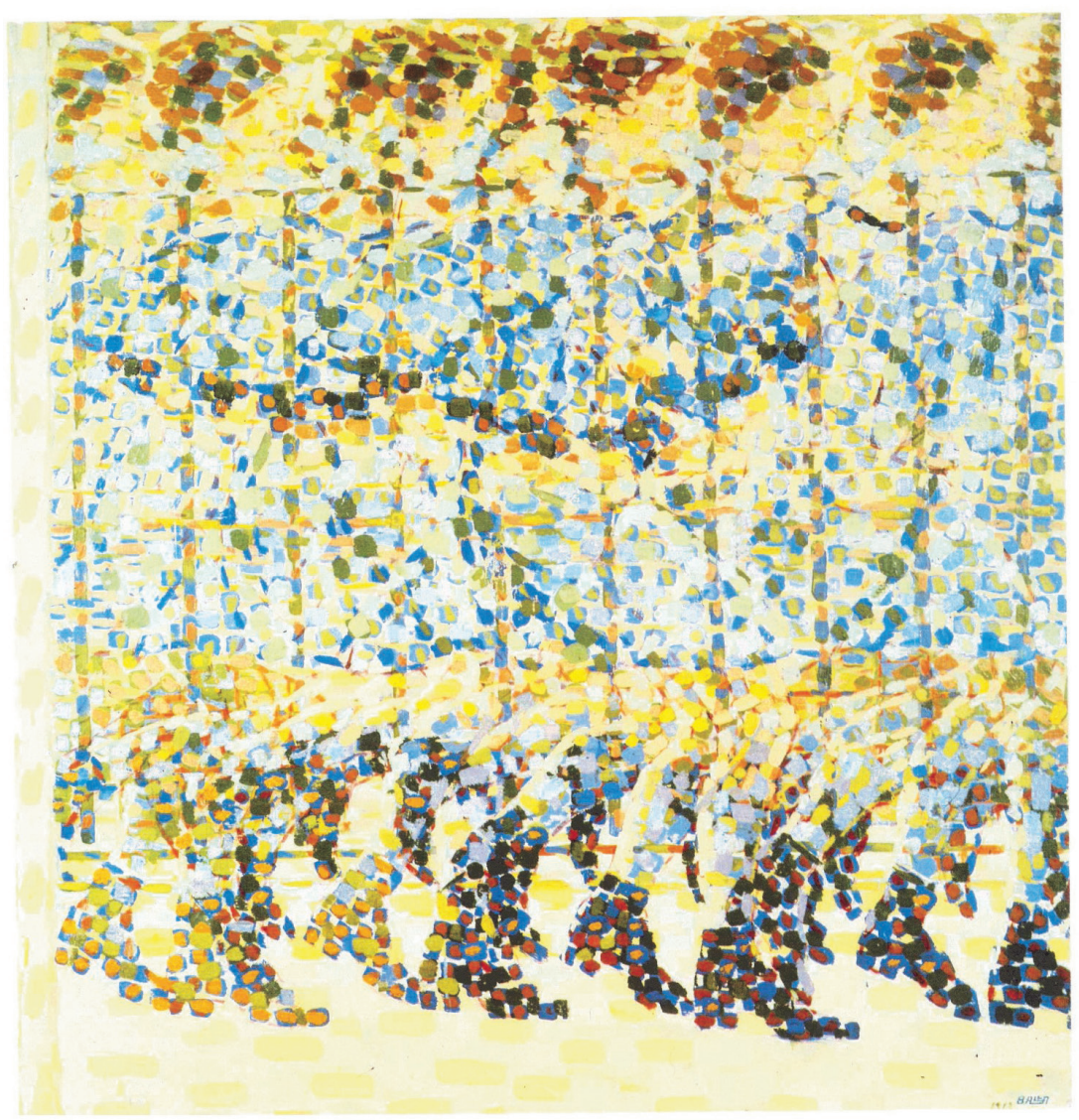

Fonte: Eco, U. e Calabrese El Tiempo en la pintura, 198, p. 115.

Nos casos vistos se utilizaram procedimentos de segmentação e de sequenciamento, além da multiplicação presente na representação do corpo da jovem e no espaço que percorre, no quadro futurista citado, por exemplo, resultando uma grande sensação de dinamismo.

Muitos outros procedimentos trouxeram novos ventos ao trabalho evolutivo das artes, por meio de artistas de vanguarda, cujas obras trazem lições inestimáveis. Muitas experimentações ocorreram bem antes do surgimento de novas tecnologias. Analisá-las pode ser uma forma agradável de educar os sentidos, de melhorar a percepção de objetos da cultura avançando no tecido de relações que ela nos propõe além do sentido óbvio.

\section{DALINIANAS}

Um dos artistas plásticos mais talentosos da contemporaneidade foi, sem dúvida, o controverso pintor catalão Salvador Dalí. Além do inegável domínio de sua arte, Dalí foi um artista muito consciente do aspecto mercadológico da pintura, ou seja, para vender a arte a bom preço, além do imprescindível 
6. TORÁN, Enrique. EI Espacio en la Imagen. De las perspectivas prácticas al espacio cinematográfico. Barcelona: Mitre, 1985 , p. 26.

7. KEEVIL, Elizabeth e EYRES, Kevin. Dalí. Madrid: Edimat Libros, S.A., 2008, p. 348. talento, era bem-vindo ser também uma celebridade. $\mathrm{O}$ artista soube vender bem a mescla de genialidade e delírio que caracterizou sua trajetória.

Dalí fez frequentes jogos com a percepção do espectador. Realizou muitos quadros em que parecia testar de forma lúdica muitas das questões abordadas pela gestalt, exigindo mais da percepção do apreciador de suas pinturas, gerando duplicidades e polissemias nas ambíguas figuras pintadas e nas relações subvertedoras que criavam na poética singular do pintor catalão.

Assim, o público de Dalí aprendeu a perceber que uma paisagem de Dalí pode esconder um rosto (El Gran Paranoico, 1936), ou um corpo (España, 1938) que uma figura pode aglutinar em si um cavalo, um leão, bem como uma mulher nua, e assim por diante (Durmiente, caballo, león invisibles, 1930).

Os jogos com a percepção tornam o espectador mais ativo e demandam uma interatividade nos moldes que se tem hoje nas artes do movimento como na TV, no cinema e nos vários suportes ou veículos da internet. E pensar que tudo isso se banalizaria ad infinitum na era da computação gráfica em que facilmente inúmeros rostos se transformam em outros tantos das mais variadas etnias num vídeoclipe do mega star Michael Jackson, procedimento que novelas da Globo, como Vamp e A próxima vítima, por exemplo, incorporaram sem o menor constrangimento na era da comunicação.

No Museu Gala-Dalí, em Figueras, na Catalunha, há um grande retângulo (4,5 x 3,5 metros) numa das paredes, feito de pixels, e que nos mostra, ora o rosto do estadista americano Abraham Lincoln, ora o corpo desnudo de uma mulher (Gala) visto de costas.

Há no quadro, entre outras, uma experimentação com o consagrado ponto de vista único e a perspectiva tal como concebidos no Renascimento ${ }^{6}$. Na obra, as estratégias de enunciação pressupõem ao menos duas possibilidades de apreensão visual que mudam de acordo com a posição ocupada diante do quadro pelo visitante do museu. Uma interatividade avant la lettre e prevista no titulo do quadro pelo genial artista: Gala desnuda mirando el mar que a 18 metros aparece el presidente Lincoln, 1973. Caso se mantenha uma perspectiva, ver-se-á Gala de costas, caso o visitante do Museu opte pela outra perspectiva unívoca indicada no titulo, verá o rosto de Abraham Lincoln.

O pintor une, de forma harmônica, a subversão aos códigos conhecidos da perspectiva renascentista a uma das novas descobertas contemporâneas: unia os pontos de meio tom ampliados, de Benday, imagens estereoscópicas e maneiras distintas de contemplar as coisas. Como havia constatado Leon Harman em artigo na Scientific American podia-se fazer um rosto reconhecível com pouca informação ao criar uma imagem de pixels em grande escala e assim chegou Dalí ao rosto de Lincoln que abriga um espaço cruciforme em seu interior imagem da eterna musa, Gala ${ }^{7}$. 
Figura II - Gala desnuda mirando al mar.

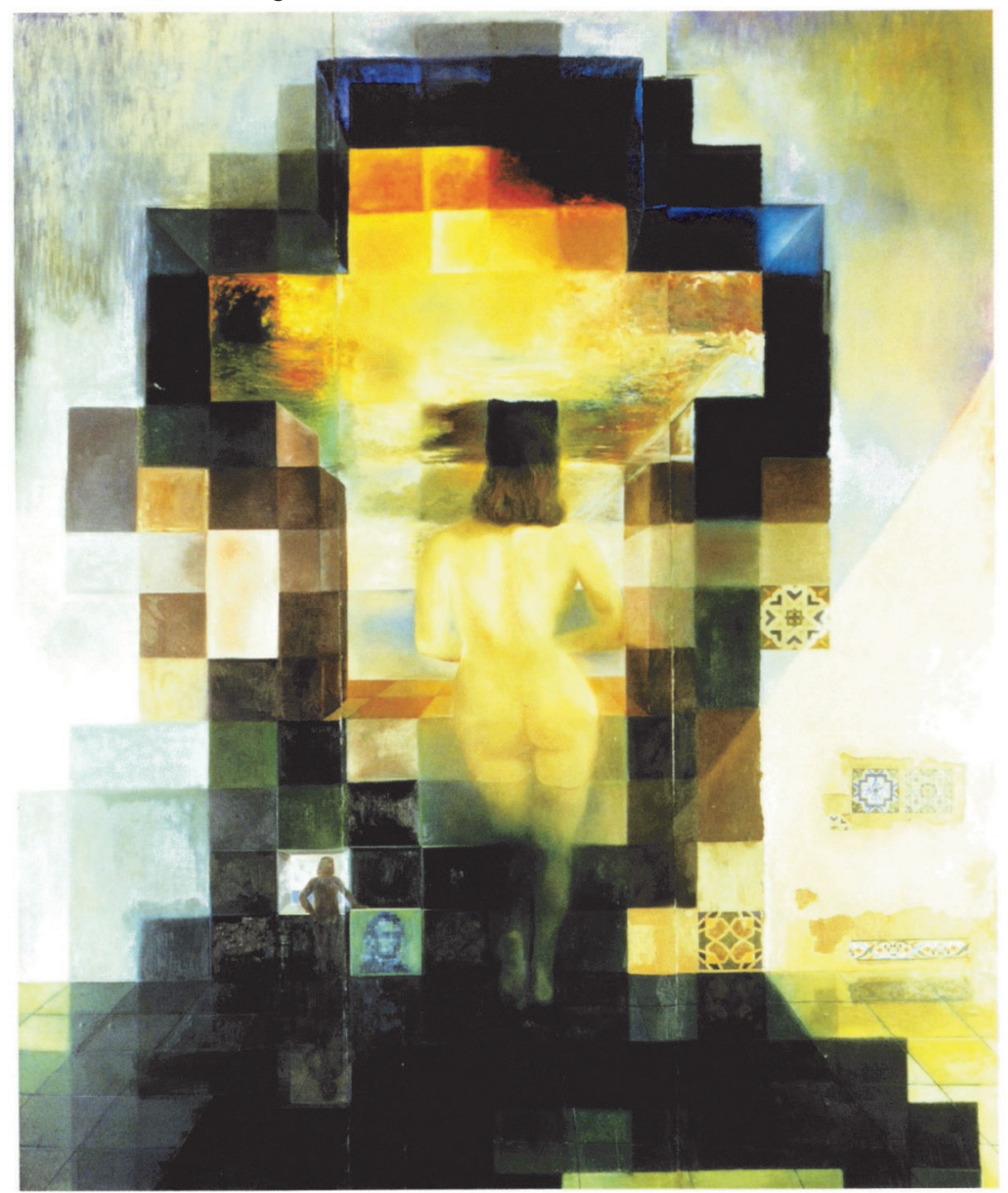

Fonte: Kevil, E. \& Kevin, E. Dalí. Madrid: Edimat, 2006, p. 349.

$\mathrm{Na}$ pintura, os artistas que subverteram de modo mais radical os cânones ditados pelas conquistas da Renascença num pretérito mais longínquo foram, sem dúvida alguma, Diego Velásquez em seu célebre quadro As Meninas, e antes dele Van Eyck em seu igualmente famoso quadro O casal Arnolfini. Em suma, Dalí teve antecessores de peso para inspirar-se em termos de experimentações subvertedoras.

Em seu desafiador One From the Heart, Francis Ford Coppola também brincou com os enquadramentos com um sentido de condensação em algumas cenas, ao dividir o quadro no sentido horizontal e unir dentro dele os dois protagonistas estranhados, bem como os espaços em que cada uma deles se encontrava, enquanto se telefonavam. Uma subversão espaço-temporal da continuidade fílmica presente na montagem clássica. Além da condensação temporal obtida pela estratégia, o realizador também utilizou o recurso teatral de privilegiar por meio da luz o ator que detinha a fala e o ponto de vista. 
A tentativa mais radical de criar uma nova forma de agenciamento dos segmentos da sintaxe fílmica, desafiando os preceitos da decupagem clássica, deve-se, no entanto, ao cineasta russo Serguei Eisenstein na sua concepção da "montagem de atrações".

A ideia do cineasta nasceu de seus estudos literários: observou ser raro que finais de capítulos coincidissem com os pontos de virada narrativos, forma que levada ao extremo, resultou nos ganchos caracterizadores do folhetim e, bem depois, da novela televisiva. Estudou ainda o modo fragmentário de conceber a arte do desenho no oriente por oposição ao modo uno de ver o objeto a ser representado no ocidente. Por fim, observou na sintagmática dos ideogramas orientais que dois ideogramas diversos justapostos resultavam num terceiro sentido diverso dos dois caracteres que o geraram, e surge dessas revisões o conceito da montagem revolucionária de filmes como O Encouraçado de Potemkine e Outubro, entre outros. Conceito que tem alguns elementos em comum com os apontados nos estudos freudianos do sonho.

Nos estudos psicanalíticos que Sigmund Freud sobre os sonhos de seus pacientes, o analista observa que os sonhos soem ser curtos e lacônicos em comparação com o volume e a riqueza dos pensamentos oníricos subjacentes que a análise expõe. Conclui que o fenômeno se deve ao fato de que o material psíquico passou por um extenso processo de condensação na formação do sonho que seria, assim, uma tradução altamente incompleta, e fragmentária dos pensamentos oníricos ${ }^{9}$.

O processo de condensação implicaria uma seleção de fragmentos que se organizariam em torno de pontos nodais para os quais convergem assuntos similares. Uma massa de pensamentos oníricos submetida a um processo manipulativo no qual os elementos com suportes mais numerosos e fortes adquirem direito de acesso ao conteúdo do sonho e outros se omitem. Há, portanto, uma seleção de fragmentos e a construção de uma trama particularmente engenhosa de relações recíprocas ${ }^{10}$.

Freud define de forma sucinta a condensação como o modo mediante o qual se dá preferência aos elementos que ocorrem várias vezes nos pensamentos do sonho, e analisa nos relatos dos pacientes como se formam novas unidades e como se constroem entidades intermediárias comuns ${ }^{11}$.

O estudo do mecanismo de condensação guarda elementos de similaridade e interseção com o conceito greimasiano de "isotopia" tal como formulado pelo mestre, ou seja, como um feixe de categorias redundantes que subjaz ao discurso, bem como com a questão dos conectores. Duas isotopias se ligam por meio de um termo conector comum, em muitos casos a identidade ou similaridade de formato é suficiente para conectar as duas isotopias ${ }^{12}$.

Como se pode observar, os feixes de categorias semânticas redundantes guardam similaridades com a preferência aos elementos recorrentes nos pensamentos do sonho, assim como os conectores de isotopias guardam semelhanças como as entidades intermediárias comuns detectadas nos sonhos pelo psicanalista. As duas concepções dialogam e se complementam.

As sínteses presentes nos sonhos podem, segundo Freud, resultar em malformações verbais ou formações verbais absurdas nas quais é possível detectar o resultado do trabalho do inconsciente ao sonhar. Estruturas do tipo em questão 
podem ser observadas em palavras como workaholic que une o trabalho e o aspecto viciador do álcool, para gerar um terceiro conceito: o caráter quase obsessivo que o trabalho adquire na vida do homem contemporâneo em certas esferas e culturas.

A pergunta que paira no ar é se seria possível a existência de algum mecanismo similar ao da condensação, dos ideogramas, da montagem de atrações, ou das formações verbais estranhas, detectável na imagem estática e como ela seria representada de forma eficaz na criação de novos sentidos. O quadro no qual Dalí parece aproximar-se mais de tais conceitos é, na verdade, Tête Raphaelesque eclatée, de 1951.

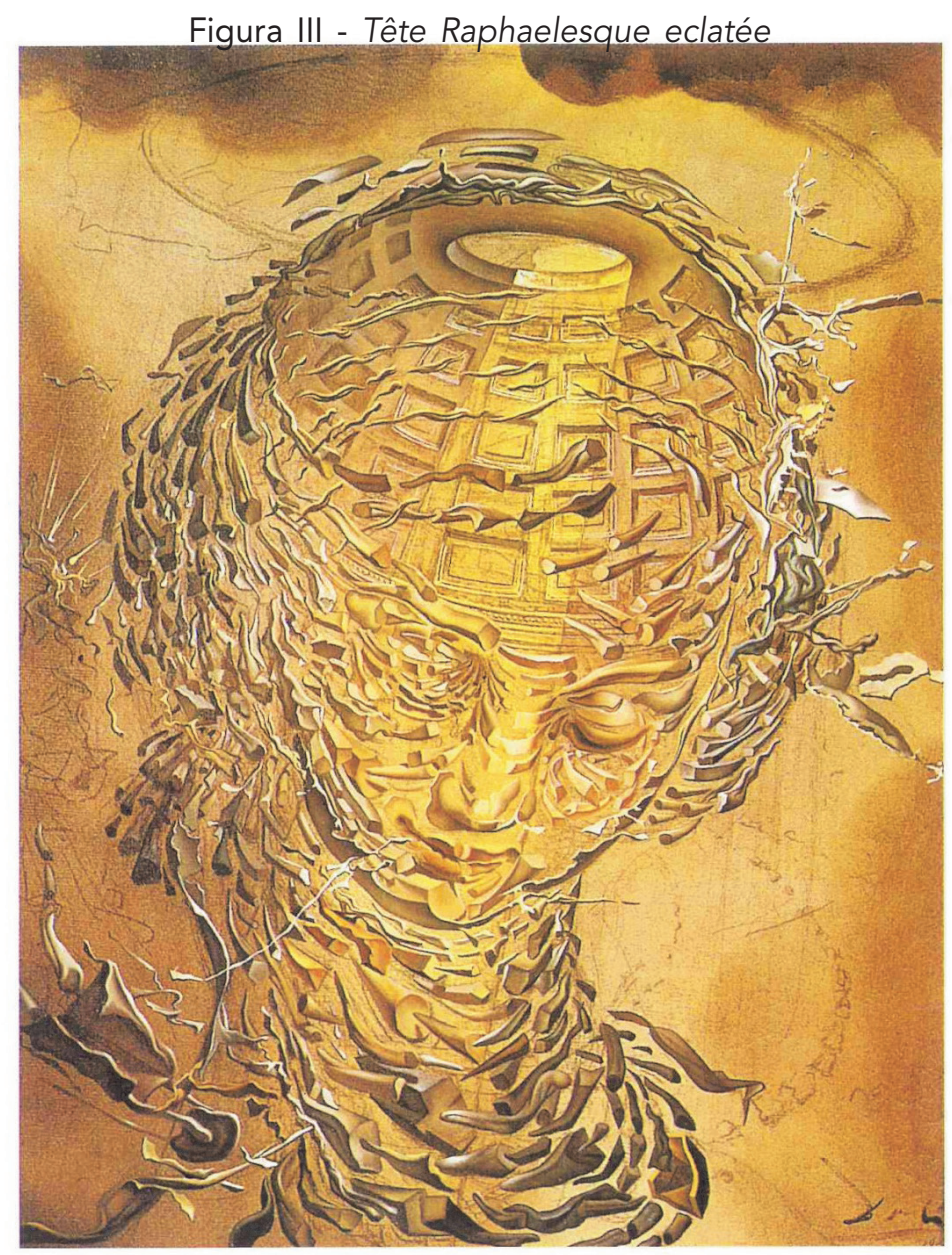

Fonte: Gilles Neret. Dalí. Koln: Taschen, 2004, p. 72.

Na obra em questão, Salvador Dalí, recorre à fusão de um rosto feminino clássico, muito belo e suave, com a elaborada estrutura da cúpula de um edifício renascentista, eventualmente uma igreja. A parte superior do rosto deixa transparecer detrás de si a estrutura da cúpula. Aqui parece que, de fato, se chega a um processo similar ao da condensação freudiana, característico do sonho, caro aos surrealistas, presente em várias obras de Luis Buñuel, com quem Dalí assinou dois filmes A Idade de Ouro e O cão andaluz. 
Na verdade, a cabeça rafaelesca remete às conquistas da arte renascentista, principal codificadora dos cânones artísticos ocidentais e, portanto, abre para um campo associativo nesse sentido, já sugerido pelo próprio título. Ou seja, encontra-se na obra um núcleo de revisão da própria diacronia da pintura, além do fazer pictórico em fusão com a arquitetura.

Por outro lado, a obra parece situar-se dentro de um veio de busca da espiritualidade próprio de uma das fases da trajetória do artista, que ele mesmo recolhe em livro ${ }^{13}$. Assim se sintetizam duas isotopias no quadro, a da busca e revisão da arte prévia e do ato de criar, bem como a questão da espiritualidade presente na arte, apesar do mundo que caminha para novas tecnologias. $\mathrm{O}$ artista concede ao espectador o prazer espiritual que reside na descoberta de suas isotopias diversas em um só discurso, como afirma Greimas no texto já citado. Em termos figurativos se retoma o simbolismo que o alto tem na cultura ocidental: a altura em termos espaciais remete de forma clara ao divino, bem como a espiritualidade humana, como enfatiza a arquitetura, sobretudo nas igrejas góticas.

Por outro lado, a cabeça, situada na parte superativa do corpo humano, remete a uma das capacidades humanas mais valorizadas, a do raciocínio. Como afirmava Blaise Pascal, o homem é um caniço,o mais fraco no âmbito da natureza, ainda assim, um caniço pensante ${ }^{14}$. A cabeça sendo o nosso órgão mais nobre se assemelha à cúpula de um edifício, forma arquitetônica que significou um desafio monumental proposto à inteligência humana e vencido com galhardia por artistas geniais.

\section{A INSTALAÇÃO: A ARTE CHEGA AO MUNDO DOS OBJETOS}

Outro processo de citações complexo, com mudanças de suporte e composto de referências a diversos âmbitos no universo da cultura, se verifica em outras obras do pintor catalão. Trata-se da visão sui-generis de Dalí no tocante a estrela Mae West, no qual a partir de uma foto da estrela americana Mae West imagina-se toda uma decoração de interior na qual terá destaque um sofá-lábios ${ }^{15}$. A foto da atriz, de 1934-5, cujo semblante se mantém na obra pictórica de Dalí notáveis semelhanças com a foto, dá origem a um intrincado tecido de relações. A imagem pictórica se transforma num apartamento surrealista, ou seja, o pictórico se metamorfoseia em outra arte mais contemporânea: a instalação, como prevê o próprio título da obra: Visage de Mae West pouvant être utilisé comme apartemement surréaliste.

No museu Gala-Dalí, em Figueras, Cataluña, a transformação do quadro em instalação torna-se uma realidade e passa-se do universo bidimensional do quadro para um espaço tridimensional, a instalação. Os cabelos de Mae West transformam-se em cortinas, seus olhos em quadros da parede. Na época em que a autora visitou o Museu de Figueras, o nariz da estrela hollywoodiana escondia, atrás, uma pequena escadaria pela qual o visitante podia subir e ver o apartamento surrealista a partir de outro ângulo, não apenas o frontal ou lateral. Nas fotos atuais da instalação esta parte parece ter sido retirada e a instalação cercada, não permitindo, o acesso ao seu interior e diminuindo o grau de inter-relação com o público. Uma grande metamorfose, ainda assim. 
Dalinianas e outras metamorfoses imagéticas - Anna Maria Balogh

Figura IV: O rosto de Mae West

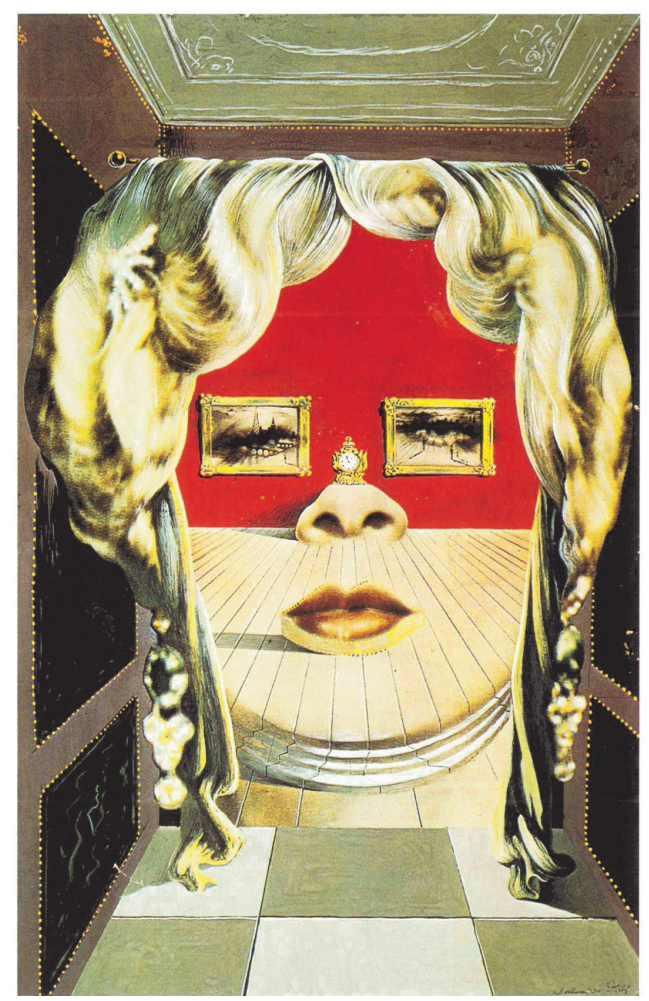

Fonte: Conroy Maddox, Salvador Dalí 1904-1989. O Gênio e o Excêntrico. Koln: Taschen, 1990, p. 42.

Figura V: Mae West (Instalação)

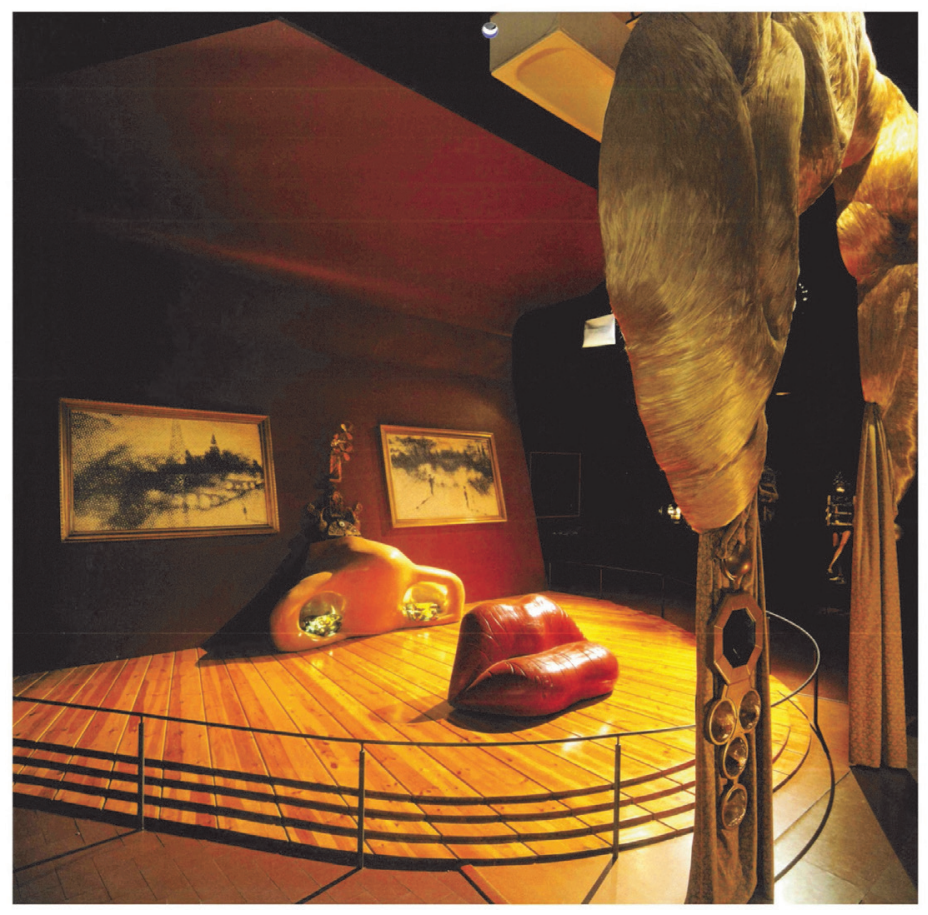

Fonte: Theatre - Museu Dalí - Calendário 2014, Triangle Postals. 
Um dos aspectos mais instigantes da instalação é o sofá que foi replicado em outros exemplares saindo, desta forma, do rarefeito universo da arte para entrar naquele dos objetos de griffe, em mais um desdobramento curioso das obras de Dalí, hoje presente no mundo de brinquedos, jogos e lembranças nascidas de filmes de sucesso.

Bem, pensado, o sofá que imitava os lábios vermelhos e carnudos de Mãe West parecia mesmo um objeto fadado a destacar-se de todos os modos, posto que é aquele que melhor traduz a intensa sensualidade da atrevida atriz. Da instalação surrealista, arte, passa-se ao âmbito refinado dos objetos de assinatura, o pequeno sofá-boca, teve inclusive uma versão em rosa shocking.

A obra de Dalí se presta de forma admirável às mais variadas metamorfoses. A possibilidade de um salto da obra artística para o exterior, o mundo dos objetos também pode ser observada em fragmentos da obra de Dalí transformados em joias ou bijuterias, em perfumes e embalagens. Neste último processo observam-se algumas etapas: a seleção de uma imagem da obra do pintor condizente com as características de um frasco, como uma figura de mulher, por exemplo, a adaptação do design às exigências do objeto. A operação pressupõe, como visto no caso do sofá, o salto do bi ao tridimensional. O objeto "perfume" prevê um contato mais íntimo e singular com a compradora, e a inclusão de novos sentidos importantes: o tato e depois o olfato, de forma diversa do quadro que originou o objeto, no qual prevalece o sentido da visão.

Quaisquer que sejam as mudanças eventuais observadas na passagem da imagem artística para o mundo dos objetos, os mesmos sempre levarão consigo o prestígio da assinatura e do renome do artista, símbolos de requinte. Objetos originados a partir de obras de arte únicas sempre provocam a cobiça, o desejo de possuir, numa sociedade como a contemporânea, posto que significam refinamento e status.

As experimentações de caráter inovador ou subversivo dos artistas mais ousados da contemporaneidade constituem um campo de grande potencial para a cultura, mas também, por suas amplas possibilidades de reaproveitamento, difusão, produção seriada, para o mundo comunicacional e mercadológico. Alimenta-se assim, tanto a arte no sentido tradicional, de uma estética da inovação subvertedora, quanto a estética da repetição, quando o massivo se apodera do que antes foi inovador e o multiplica. O novo alimenta-se do prévio com um novo olhar estabelecendo novas reaproximações inéditas. Em suma, cada intervenção sobre o mundo das imagens conhecido, traz a possibilidade de uma visão de mundo ainda desconhecida e surpreendente.

A arte também significa desafio de leitura, densidade dos sentidos, prazer de ver, descobrir novas formas, novas visões no seu metamorfosear incessante que nos desafia e nos convida, uma e outra vez, a decifrar. Quanto maior o desafio, mais encanta ao público e mais instiga a critica, ambos sempre a espera

16. ROJAS MIX, Miguel. El Imaginario. Civilización y Cultura del Siglo XXI. Buenos Aires: Prometeo Libros, 2006, p. 523.

de novas subversões. 


\section{REFERÊNCIAS}

DICIONÁRIO DA TV GLOBO. Programas de Dramaturgia \& Entretenimento. Rio de Janeiro: Jorge Zahar Editor, 2003, v. 1.

ECO, U. \& CALABRESE, O. El Tiempo en la Pintura. Milan: Mondadori, 1987.

EISENSTEIN, S. The Cinematographic Principle and the Ideogram. In: MAST, G. e COHEN, M. NY- Oxford: oxford University Press, 1985: 90-103.

FREUD, Sigmund. A Interpretação dos Sonhos. São Paulo: Círculo do Livro, v. $1, \mathrm{~S} / \mathrm{d}$.

GREIMAS, A. Julien. Du Sens. Essais Semiotiques. Paris: Eds. Du Seuil, 1970.

VERDONE, M; MIRACCO R. Giacomo Balla 1894-1946. Da io Balla a Ball'io.

Mostra e Catálogo. São Paulo: Pinacoteca do Estado, 12 de maio - 30 de jun., 2000.

KEEVIL, Elizabeth e EYRES, Kevin. Dalí. Madrid: Edimat Libros, S.A. 2008.

KARNEY, Robin. (Ed.) Chronicle of the Cinema. 100 Years of the Movies. New York: Dorling Publishing Inc., 1995.

LAGARDE, Andre \& MICHARD, Laurent. XVIIe Siecle. Les Grands Auteurs Français du Programme. France, Bordas, 1965.

LiCHTEnSteIn, Jacqueline (org.). A Pintura. Vol. 6. A Figura Humana. São Paulo: Editora 34, 2004.

LOTMAN, Iuri. La Memoria a la Luz de la Culturologia. In: Criterios - Revista de la Literatura y las Artes, Estética y Culturologia. La Habana-Cuba, EneroJunio 1994, n. 31, p. 223-228.

LYOTARD, J. François. A Condição Pós-Moderna. Lisboa: Gradiva, 1989.

PORTÁS PEREZ, Javier. Fábulas de Velásquez. Mitología e Historia Sagrada en el Siglo de Oro. Madrid: Museo del Prado, 2007.

ROJAS MIX, Miguel. El Imaginario. Civilización y Cultura del Siglo XXI. Buenos Aires: Prometeo Libros, 2006.

SILVA, Ignácio Assis. Figurativização e Metamorfose. O mito de Narciso. São Paulo: Editora da UNESP, 1995.

TORÁN, Enrique. El Espacio en la Imagen. De las perspectivas prácticas al espacio cinematográfico. Barcelona: Mitre, 1985.

VIRILIO, Paul \& LOTRINGER, S. Guerra Pura: A Militarização do Cotidiano. São Paulo: Brasiliense, 1984. 